\title{
Pirólise rápida de biomassa de eucalipto na presença de catalisador Al-MCM-41
}

\author{
Camila Ribeiro de Oliveira Félix ${ }^{1,2}$, Aroldo Félix de Azevedo Júnior ${ }^{1,3}$, \\ Carolina Costa Freitas ${ }^{1}$,Carlos Augusto de Moraes Pires ${ }^{1}$, Victor Teixeira ${ }^{4}$, \\ Roger Frety ${ }^{1}$, Soraia Teixeira Brandão ${ }^{1}$
}

\author{
${ }^{1}$ Laboratório de Catálise e Polímeros - LabCat - PPEQ/UFBA, CEP 40210-630, Salvador, Brasil. ${ }^{2}$ Petróleo e Gás - \\ Instituto Federal de Educação, Ciências e Tecnologia da Bahia - IFBA, CEP 43700-000, Simões Filho - BA. ${ }^{3}$ Centro de \\ Ciência e Tecnologia em Energia e Sustentabilidade/UFRB, CEP 44042-280, Feira de Santana - BA. ${ }^{4}$ Núcleo de Catálise \\ - NUCAT/COPPE/UFRJ, CEP 21941-916, Rio de Janeiro - RJ. \\ e-mail: camila_rib@yahoo.com.br
}

\begin{abstract}
RESUMO
A América Latina possui um considerável potencial na produção de biomassa, se destacando principalmente pela utilização de seus resíduos, sendo o Brasil um dos representantes mais importantes na geração de energia proveniente dessas fontes renováveis. Nesse sentido, esse trabalho aborda a biomassa de eucalipto, na forma de resíduo, como uma fonte promissora e de baixo custo para produção de energia e de produtos químicos. O objetivo do trabalho é realizar a pirólise rápida a temperatura de $500{ }^{\circ} \mathrm{C}$ na presença de catalisador mesoporoso Al-MCM-41 visando avaliar o rendimento das fases (bio-óleo, bio-gás e bio-carvão), bem como analisar os produtos gerados na fase líquida utilizando um cromatógrafo a gás com um espectrômetro de massas acoplado. Foram realizadas caracterizações por microscopia eletrônica de varredura (MEV) e fluorescência de raios X (FRX) para o catalisador e a biomassa, além de análise elementar, imediata, poder calorífico e análise termogravimétrica (ATG) para o eucalipto. Foram obtidos rendimentos de bio-óleo, bio-gás e bio-carvão, compatíveis com a literatura, além de comprovar que a presença do catalisador influencia de forma direta nesta distribuição. Os principais compostos identificados foram o ácido acético, 1-hidroxi - 2propanona, 1-1-dietoxi-etano, furfural, confirmando a importância do processo para obtenção de produtos químicos.
\end{abstract}

Palavras-chave: Resíduo, Processo Térmico, Bio-óleo.

\begin{abstract}
Latin America has considerable potential in the production of biomass, mainly for the use of its waste, Brazil being one of the most important representatives in the generation of energy from these renewable sources. In this sense, the paper approaches eucalyptus biomass, in the form of residue, as a promising source of low cost for the production of energy and chemical products. The objective of this work is to perform the fast pyrolysis at $500{ }^{\circ} \mathrm{C}$ in the presence of mesoporous Al-MCM-41 catalyst to evaluate the performance of the phases (bio-oil, biogas and bio-coal), as well as to analyze the products generated in the liquid phase using a gas chromatograph with a coupled mass spectrometer. The catalysts and the biomass were characterized by scanning electron microscopy (SEM) and X-ray fluorescence (FRX). Elemental analysis, immediate analysis, calorific value and thermogravimetric analysis were performed for eucalyptus. Bio-oil, bio-gas and biocarbon yields were obtained, compatible with the literature, besides proving that the presence of the catalyst influences directly in this distribution. The main compounds identified were acetic acid, 1-hydroxy-2propanone, 1-1-diethoxyethane, furfural, confirming the importance of the process for obtaining chemical products.
\end{abstract}

Keywords: Residue, Thermal Process, Bio-oil.

\section{INTRODUÇÃO}

Atualmente a maioria dos países está promovendo ações que visam à utilização de fontes renováveis de energia para reduzir o uso dos derivados de petróleo e, consequentemente, a dependência energética em relação aos países exportadores. A Agência Internacional de Energia (AIE) calcula que dentro de aproximadamente 
20 anos, cerca de $30 \%$ do total de energia consumida pela humanidade será proveniente das fontes renováveis, que hoje apresentam $14 \%$ da energia produzida no mundo, em que a biomassa tem $11,4 \%$ na participação da oferta [1].

Em 2014, a participação de energias renováveis na Matriz Energética Brasileira manteve-se entre as mais elevadas do mundo, com pequena redução devido á menor oferta de energia hidráulica As fontes de energia renováveis correspondem à biomassa $(15,7 \%)$, hidráulica $(11,5 \%)$, lenha e carvão vegetal $(8,1 \%)$, lixivia e outras renováveis $(4,1 \%)$. Enquanto que as provenientes de fontes não renováveis englobam petróleo e derivados $(39,4 \%)$, gás natural $(13,5 \%)$, carvão mineral $(5,7 \%)$, urânio $(1,3 \%)$ e outras não renováveis $(0,6 \%)[2]$.

A biomassa, também considerada como uma fonte promissora de energia a qual pode ser obtida de vegetais não lenhosos ou lenhosos, como é o caso da madeira e seus resíduos, e também de resíduos orgânicos, nos quais encontramos os resíduos agrícolas, urbanos e industriais. As características e disponibilidade regional da biomassa são definidas como um conjunto de indicadores para sustentabilidade, em especial com foco no meio ambiente e aplicação de critérios socioeconômicos $[1,3]$.

O resíduo florestal é caracterizado como o material que é descartado na etapa da coleta da madeira, tanto em florestas e bosques naturais como em reflorestamento, e pela serragem e aparas produzidas no processamento da madeira [1].

Embora grande parte dos resíduos agroindustriais já possua aplicação definida, a biomassa residual de atividades agrícolas ainda não é bem utilizada no Brasil. Em muitos casos é deixada para decomposição natural do solo, sem aproveitamento da energia nela contida e produzindo gás carbônico e metano. Os resíduos até agora representam um potencial de energia ainda inexplorado em todo o mundo [4].

Para esse trabalho foi escolhido a biomassa de eucalipto na forma de resíduos (cavacos). Se trata de uma espécie com área plantada de cerca de 6,4 milhões de hectares no Brasil, ser uma árvore de crescimento rápido, possuir variados fins de utilização e apresentar baixo teor de cinzas que reduz os potenciais efeitos indesejáveis durante a pirólise catalítica [5].

A conversão de biomassa em energia pode ser realizada por processos termoquímicos, biológicos, mecânicos e físicos. Como exemplos de processos termoquímicos têm-se a combustão, a gaseificação e a pirólise $[6,7]$.

A pirólise é definida como um processo de decomposição térmica da biomassa na presença controlada de oxigênio e que tem como produtos compostos na fase gasosa, líquida e sólida. O gás é composto por $\mathrm{CO}$, $\mathrm{CO}_{2}$, hidrogênio e hidrocarbonetos de baixa massa molar. O líquido obtido é oriundo da condensação de gases, denominada líquido pirolenhoso, e o sólido é denominado de bio-carvão $[8,9,10]$.

A termoconversão implica na ruptura da ligação carbono-carbono e na formação das ligações carbono-oxigênio. Além de ser um processo de oxidação-redução no qual uma parte da biomassa é reduzida a carbono, enquanto a outra é oxidada e hidrolisada dando origem a fenóis, carboidratos, álcoois, aldeídos, cetonas e ácidos carboxílicos, entre outros. Esses produtos primários se combinam entre si para formação de moléculas mais complexas, tais como ésteres, produtos poliméricos, entre outros $[1,11]$.

O uso de catalisador além de acelerar as reações, pode também induzir a conversão dos reagentes na formação majoritária dos produtos mais desejados. Os catalisadores afetam de modo significativo a distribuição de produtos na reação. O catalisador utilizado nesse trabalho foi o Al-MCM-41, o qual faz parte do grupo das peneiras moleculares. Possui um arranjo hexagonal de mesoporos uniformes $(1,4-10 \mathrm{~nm})$, elevada área superficial específica $\left(>1000 \mathrm{~m}^{2} \cdot \mathrm{g}^{-1}\right)$, volume total de poros igual a $1,26 \mathrm{~mL} \cdot \mathrm{g}^{-1}$, elevada estabilidade térmica (superior a $1000{ }^{\circ} \mathrm{C}$ ) e acidez moderada. A combinação do tamanho e forma dos poros, acidez e propriedades dos metais de transição impregnados na peneira molecular auxiliam a quebra das moléculas de alto peso molecular dos materiais lignocelulósicos, formando líquidos com menos compostos oxigenados e com maior poder calorífico $[12,13,14]$.

Um catalisador apropriado para o processo de pirólise, pois não reduz de forma significativa o rendimento orgânico e não é rapidamente desativado por coque [13, 15]. Nesse sentido, este trabalho teve como objetivo analisar a pirólise rápida da madeira de eucalipto e avaliar o catalisador mesoporoso do tipo AlMCM-41 visando conhecer a natureza dos produtos da reação.

\section{MATERIAL E MÉTODOS}

\subsection{Síntese do catalisador}


A peneira molecular Al-MCM-41 foi sintetizada com razão sílica/alumina (SAR) igual a 20 segundo adaptação quanto ao tempo de reação de acordo com a metodologia proposta por BARBOSA e colaboradores [16]. Foram utilizados a sílica comercial (Aerosil) e aluminato de sódio como fontes de $\mathrm{Si}$ e $\mathrm{Al}$, respectivamente. Como agente direcionador foi utilizado cloreto de hexadeciltrimetilamônio (CTMA), na forma de solução aquosa $25 \%$ p/p. Para manter o pH básico, foi utilizada solução de hidróxido de sódio ( $\mathrm{NaOH}) 50 \% \mathrm{p} / \mathrm{p}$. As composições molares no gel de síntese foram iguais a $1 \mathrm{SiO}_{2}: 0,05 \mathrm{Al}_{2} \mathrm{O}_{3}: 0,1 \mathrm{Na}_{2} \mathrm{O}: 0,3 \mathrm{CTMA}: 26 \mathrm{H}_{2} \mathrm{O}$.

Inicialmente a solução de hidróxido de sódio e o aluminato de sódio foram lentamente adicionados, sob agitação vigorosa e constante, à solução de hexadeciltrimetilamônio, até que a dissolução do aluminato fosse completa. A sílica e a água foram misturadas em um recipiente a parte para formação do gel. Em seguida as duas suspensões foram misturadas e mantidas sob agitação por meia hora, à temperatura ambiente. A mistura foi então colocada em autoclave sem agitação e aquecida em estufa a $150{ }^{\circ} \mathrm{C}$, por 48 horas.

$\mathrm{O}$ gel de síntese filtrado e lavado com água deionizada, até que o $\mathrm{pH}$ do filtrado fosse reduzido a pelo menos 8 . O sólido foi então seco em estufa a $120^{\circ} \mathrm{C}$, por uma noite. Após a secagem, o material foi calcinado para a remoção do agente direcionador remanescente na estrutura porosa.

A calcinação foi realizada em tubo de quartzo, a temperatura de $550{ }^{\circ} \mathrm{C}$, paga garantir a remoção do direcionar de estrutura dos poros do catalisador . A etapa inicial foi realizada sob atmosfera inerte de nitrogênio a vazão de $50 \mathrm{~mL} \cdot \mathrm{min}^{-1}$, aquecimento até temperatura de $370{ }^{\circ} \mathrm{C}$ a uma taxa de $10{ }^{\circ} \mathrm{C} \cdot \mathrm{min}^{-1}$. O uso de atmosfera inerte impede a queima do composto orgânico que agiu como direcionador, com a consequente produção de vapor d'água, que poderia remover todo ou parte do alumínio incorporado à estrutura da AlMCM-41. Em seguida como a maior parte do direcionador já havia sido removida o nitrogênio foi então substituído por ar sintético com a mesma vazão e taxa de aquecimento. A temperatura foi mantida em $550{ }^{\circ} \mathrm{C}$ por mais 7,5 horas, para a combustão do material restante.

\subsection{Caracterização da biomassa}

A biomassa de eucalipto foi caracterizada por meio de fluorescência de raios X (FRX), análise termogravimétrica (ATG) e microscopia eletrônica de varredura (MEV). As medidas de fluorescência de raios X foram realizadas em equipamento Shimadzu, modelo XRF-1800. Foram preparadas misturas de 0,015g de ácido boro e $0,015 \mathrm{~g}$ de amostra e em seguida analisadas na forma de pastilhas. Para a análise termogravimétrica as amostras foram conduzidas em equipamento Shimadzu, modelo TGA-50, sob vazão constante de $50 \mathrm{~mL} \cdot \mathrm{min}^{-}$ ${ }^{1}$ de nitrogênio a temperatura de $1000^{\circ} \mathrm{C}$, sendo utilizada uma taxa de aquecimento de $10^{\circ} \mathrm{C} \cdot \mathrm{min}^{-1}$.

$\mathrm{Na}$ microscopia eletrônica de varredura foi utilizado um aparelho JEOL - JSM6610LV, as amostras foram montadas em um portador de amostras de alumínio, utilizando fita de carbono dupla face. Todas as amostras foram revestidas com material condutor antes de observar as superfícies.

Análise elementar de um sólido é um parâmetro importante para o balanço de massa e de energia nos processos de conversão termoquímica. Inclui a determinação dos teores de $\mathrm{C}, \mathrm{H}, \mathrm{N}, \mathrm{S}$ e O. Para madeira e derivados e resíduos sólidos urbanos (RSU) as diretrizes estão descritas na norma ASTM E 870 -82 (ASTM, 1982).

As análises de resíduo de carbono foram realizadas em equipamento Micro carbon residue tester, tipo ACR-M3, marca Tanaka Scientific. Os testes foram realizados de acordo com a Norma ASTM D-4530. Para determinar o poder calorífico foi usado o equipamento Calorímetro, modelo 6400 Calorimeter, da Marca Parr.

\subsection{Teste catalítico}

O eucalipto adquirido na forma de cavaco foi seco a $90{ }^{\circ} \mathrm{C}$ para remoção de umidade e em seguida triturado e separado em peneiras entre 60 e 32 mesh. O sistema de pirólise rápida foi constituído por um reator tubular de $3 \mathrm{~cm}$ de diâmetro e $70 \mathrm{~cm}$ de comprimento e uma cesta cilíndrica em malha de aço, com dimensões de 2 $\mathrm{cm}$ de diâmetro e $12 \mathrm{~cm}$ comprimento.

$\mathrm{Na}$ base do reator foi acoplado um condensador para armazenar os vapores da pirólise. Os produtos formados foram direcionados a um erlenmeyer para coleta do líquido e com o auxílio de um precipitador elestrostático ocorreu a captura de aerossóis decorrentes da pirólise da biomassa. Os vapores não condensáveis $\left(\mathrm{CO}, \mathrm{CO}_{2}, \mathrm{CH}_{4}, \mathrm{H}_{2}, \mathrm{C}_{2}\right.$ e $\left.\mathrm{C}_{3}\right)$ foram direcionados para um filtro de lã para evitar que finos ou compostos não condensáveis passassem para a linha do micro cromatógrafo a gás Agilent, onde foi realizada a análise em linha dos gases produzidos durante a pirólise.

A análise da composição dos gases provenientes da pirólise foi efetuada utilizando-se um micro cromatógrafo a gás (Agilent, modelo 490) em linha com o reator, com detector de condutividade térmica e que utiliza hélio como gás de arraste. 
O nitrogênio foi direcionado ao controlador de vazão e as vazões foram estabelecidas em um painel de controle, antes de serem direcionadas ao sistema. O gás foi preaquecido ao passar por uma serpentina situada envolta do reator.

Os gases gerados no processo de pirólise foram analisados em linha com o pirolisador e foram coletados em intervalos de 6,5 minutos ao longo de todo o processo de pirólise. O tempo de amostragem do gás foi de 30 segundos e o tempo de análise foi 6 minutos.

Foram utilizados $11 \mathrm{~g}$ de biomassa de eucalipto compactadas em uma cesta cilíndrica situada no interior do reator. Para os testes catalíticos foram utilizados 5,5 g de Al-MCM-41 previamente aquecidos para remoção da umidade.

Os produtos líquidos foram analisados utilizando-se um cromatógrafo a gás com um espectrômetro de massas acoplado (Agilent, modelo 7890A/5975 VL) e equipado com um injetor automático (Agilent, modelo G4513A). O cromatógrafo era dotado de um detector tipo ionização de chama.

A coluna cromatográfica utilizada foi da Agilent, modelo 19091S-433 de $30 \mathrm{~m}$ de comprimento, 250 $\mu \mathrm{m}$ de diâmetro interno e $0,25 \mu \mathrm{m}$ de filme. Como gás de arraste foi usado He e a razão de split foi de 1:10. Durante a análise das amostras líquidas, as temperaturas do injetor, detector e interface foram mantidas a 260 , 270 e $280^{\circ} \mathrm{C}$, respectivamente.

Devido à alta viscosidade do líeuido pirolenhosos, as amostras coletadas durante a reação foram diluídas em etanol na razão 1:3 e uma alíquota de $0,5 \mu \mathrm{L}$ desta mistura foi usada na separação cromatográfica.

A identificação dos picos cromatográficos foi realizada de acordo com a biblioteca do NIST MS. Os compostos identificados foram separados nas seguintes classes químicas: ácidos carboxílicos, álcoois, aldeídos, cetonas, éteres, ésteres, compostos fenólicos (fenóis), compostos furânicos (furanos) e açúcares, e os não identificados foram indicados pela sigla N.I.

\section{RESULTADOS}

A microscopia eletrônica de varredura foi empregada com a finalidade de observar a morfologia e distribuição do tamanho de partícula e homogeneidade das amostras. As amostras foram revestidas com material condutor antes de observar as superfícies. Na Figura 1, está apresentada a micrografia da amostra Al-MCM-41 com ampliação de $180 \mathrm{x}$.

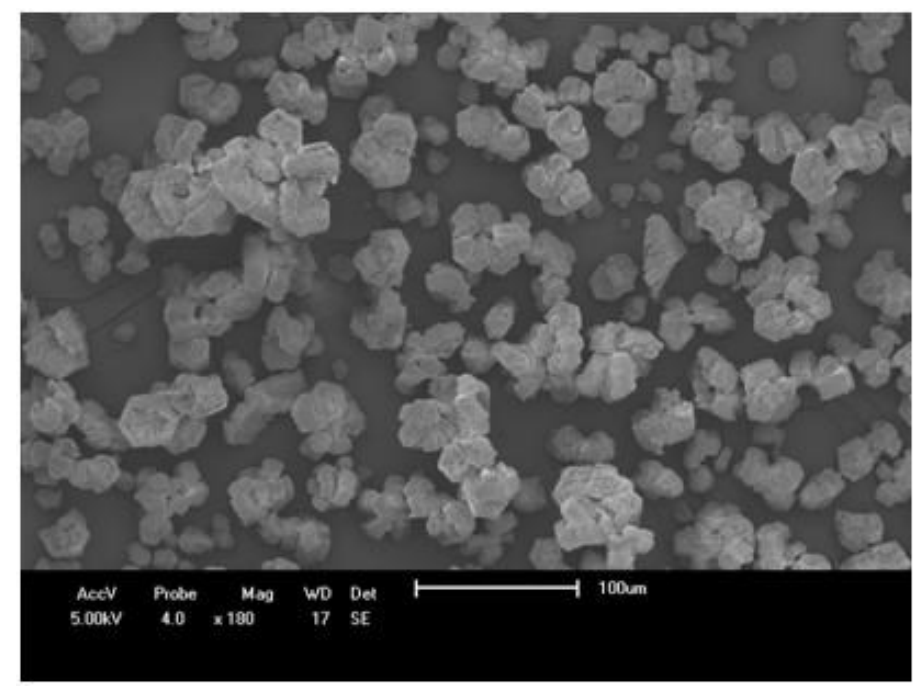

Figura 1: Microscopia eletrônica de varredura da Al-MCM-41 com ampliação de 180x.

As medidas de fluorescência de raios X foram realizadas para a Al-MCM-41 observando 92,7 m/m para $\mathrm{SiO}_{2}, 6,6 \mathrm{~m} / \mathrm{m} \mathrm{Al}_{2} \mathrm{O}_{3}$ e razão silício alumínio $\mathrm{SiO}_{2} / \mathrm{Al}_{2} \mathrm{O}_{3}$ igual a $23,7 \mathrm{~m} / \mathrm{m}$.

O conhecimento da estrutura e das propriedades da biomassa é de fundamental importância para compreensão dos produtos pós-processamento. Para determinar a potencialidade de um combustível e, portanto, poder avaliar se este está sendo utilizado dentro de sua plena capacidade, deve-se primeiramente conhecer as suas características químicas e térmicas fundamentais, ou seja, sua composição química e seu potencial calórico. 
Neste sentido, são apresentados nas Tabelas 1 e 2 resultados de composição elementar, composição imediata, poder calorifico, além das propriedades inorgânicas da biomassa de eucalipto.

Tabela 1: Análise elementar, imediata e poder calorífico da biomassa de eucalipto.

\begin{tabular}{c|c}
\hline ANÁLISE ELEMENTAR $(\% \mathbf{p} / \mathbf{p})$ & \\
\hline Carbono $(\mathrm{C})$ & 45,5 \\
\hline Hidrogênio (H) & 7,8 \\
\hline Nitrogênio (N) & 0,2 \\
\hline Oxigênio (O) & 46,5 \\
\hline ANÁLISE IMEDIATA (\% p/p) & \\
\hline Umidade & 10,9 \\
\hline Carbono fixo & 26,0 \\
\hline PODER CALORÍFICO (MJ/Kg) & 17,5 \\
\hline
\end{tabular}

Tabela 2: Propriedades inorgânicas de amostras de biomassa (\% em peso de cinzas).

\begin{tabular}{c|c}
\hline COMPOSIÇÃo QUÍMICA DA CINZA & EUCALIPTO $\%(\mathbf{p} / \mathbf{p})$ \\
\hline Carbono (C) & 98,12 \\
\hline Cálcio (Ca) & 0,19 \\
\hline Magnésio (Mn) & 0,08 \\
\hline Potássio (K) & 0,18 \\
\hline Silício (Si) & 1,05 \\
\hline Ferro (Fe) & 0,06 \\
\hline Fósforo (P) & 0,04 \\
\hline Enxofre (S) & 0,05 \\
\hline Alumínio (Al) & 0,15 \\
\hline
\end{tabular}

A Análise Termogravimétrica (TGA) é uma ferramenta importante utilizada na caracterização da biomassa. É utilizada para quantificar a perda de peso de uma amostra em relação a temperatura e tempo e estudado o comportamento da decomposição e a cinética térmica dos materiais orgânicos. Um conhecimento abrangente de análise termogravimétrica (TGA) e cinética de volatilização durante a pirólise podem facilitar o desenvolvimento (planejamento e projeto) e operação da indústria de pirólise. Na Figura 2 é apresentado o perfil de TG e DTG da amostra de eucalipto até $1000{ }^{\circ} \mathrm{C}$ com as respectivas regiões de perda de massa.

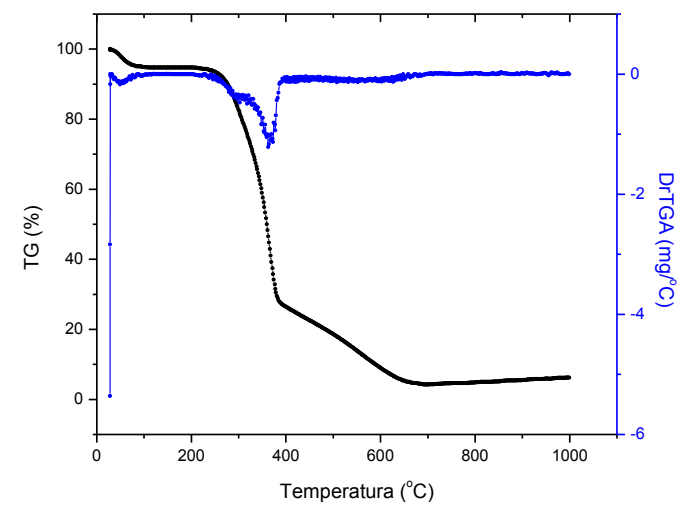

Figura 2: Perfis da análise termogravimétrica da biomassa de eucalipto. 
A técnica de microscopia eletrônica de varredura foi utilizada com objetivo de estudar a estrutura fibrosa da madeira a ser processada por pirólise rápida. Na Figura 3 estão apresentadas as microscopias da biomassa de eucalipto com ampliação de ampliações de 200 e 400x.
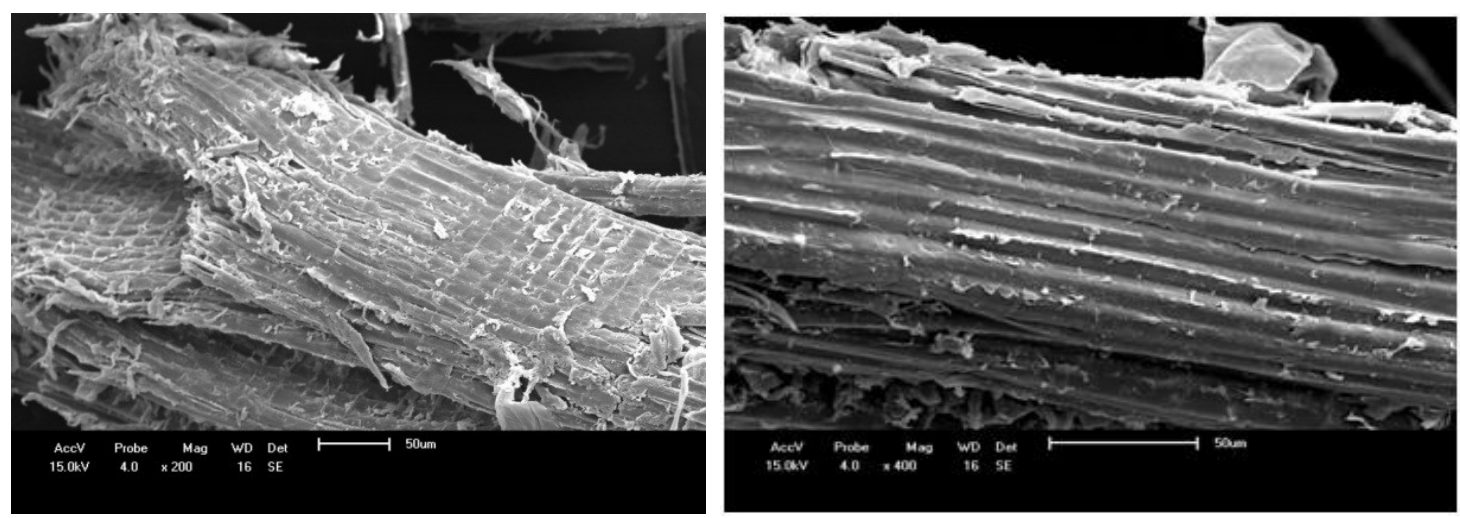

Figura 3: Microscopia eletrônica de varredura da biomassa de eucalipto com ampliação de 200 x.

Para pirólise rápida da biomassa de eucalipto o rendimento dos produtos foi calculado em base seca e livre de cinzas, ou seja, no cálculo foi descontado a água e as cinzas presentes na biomassa. Na Figura 4 é apresentado o rendimento médio de líquido pirolenhoso, bio-carvão e bio-gás, obtidos na pirólise do eucalipto e com o catalisador à temperatura de $500^{\circ} \mathrm{C}$.

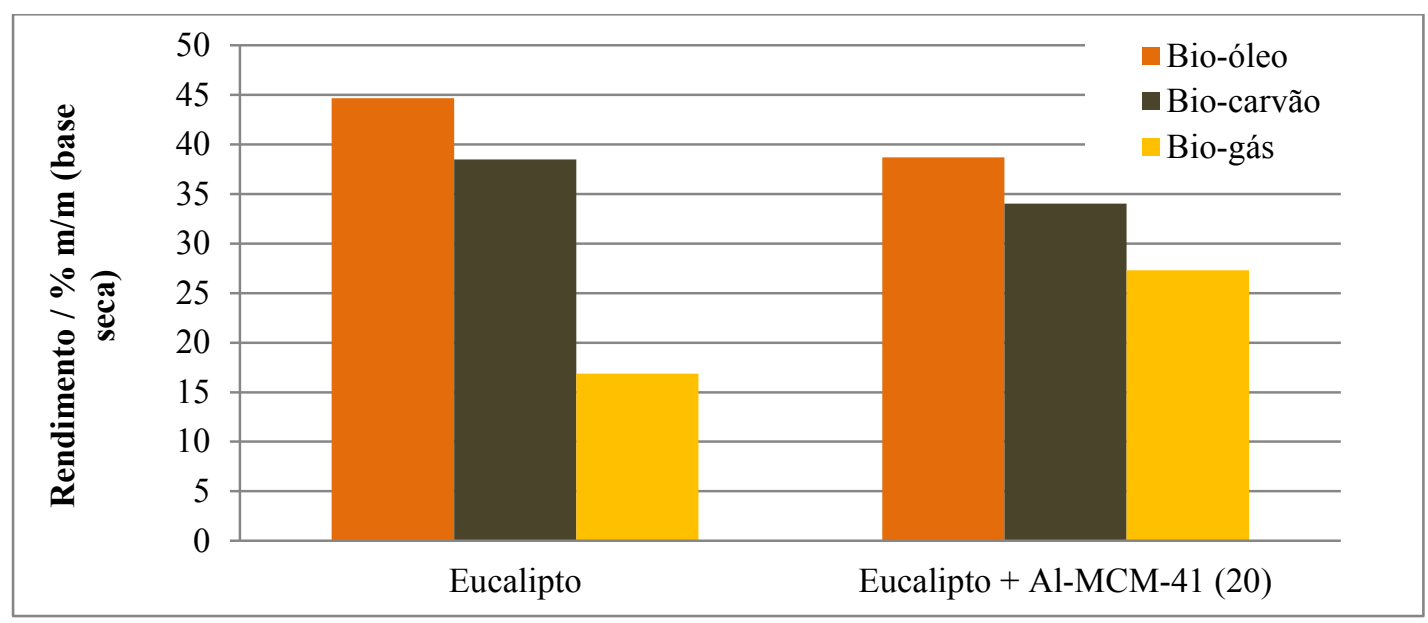

Figura 4: Rendimento dos produtos da pirólise.

A identificação dos compostos presentes no líquido pirolenhoso foi realizada através da análise cromatográfica acoplada à espectrometria de massas (CG-MS), permitindo a identificação de aproximadamente $98 \%$ dos compostos.

Durante o processo de conversão da biomassa são consideradas as reações de hidrogenação, hidrogenólise, descarboxilação, descarbonilação, hidrocraqueamento e polimerização que dão origem a produtos como ésteres, cetonas, fenóis, aldeídos, álcoois, éteres e hidrocarbonetos [11].

Com o objetivo de facilitar a análise dos produtos da pirólise, estão apresentados na Tabela 3 os compostos detectados no líquido pirolenhoso com seus respectivos tempos de retenção, fórmula química e porcentagem em área. 
Tabela 3: Compostos presentes no bio-óleo identificados por CG/EM.

\begin{tabular}{|c|c|c|c|c|c|}
\hline & & & & Eucalipto & $\begin{array}{c}\text { Eucalipto +Al- } \\
\text { MCM-41 }\end{array}$ \\
\hline & RT (min) & COMPONENTES & FÓRMULA & \multicolumn{2}{|c|}{ ÁREA (\%) } \\
\hline 1 & 2,70 & 3-metil-2-butanona & $\mathrm{C}_{5} \mathrm{H}_{10} \mathrm{O}$ & - & 0,94 \\
\hline 2 & 2,79 & 2-butanona & $\mathrm{C}_{4} \mathrm{H}_{8} \mathrm{O}$ & - & 1,90 \\
\hline 3 & 2,95 & Etil acetato & $\mathrm{C}_{4} \mathrm{H}_{8} \mathrm{O}_{2}$ & 3,02 & 10,02 \\
\hline 4 & 3,72 & Ácido acético & $\mathrm{C}_{2} \mathrm{H}_{4} \mathrm{O}_{2}$ & 25,51 & 35,59 \\
\hline 5 & 3,87 & 1-hidroxi - 2-propanona & $\mathrm{C}_{3} \mathrm{H}_{6} \mathrm{O}_{2}$ & 7,94 & 7,60 \\
\hline 6 & 4,91 & 1,1-dietoxi-etano & $\mathrm{C}_{6} \mathrm{H}_{14} \mathrm{O}_{2}$ & 4,22 & 6,92 \\
\hline 7 & 6,24 & 1-hidroxi-2-butanona & $\mathrm{C}_{4} \mathrm{H}_{8} \mathrm{O}_{2}$ & 1,98 & 1,13 \\
\hline 8 & 6,83 & Ciclopentanona & $\mathrm{C}_{5} \mathrm{H}_{8} \mathrm{O}$ & - & 0,98 \\
\hline 9 & 7,47 & Trietoximetano & $\mathrm{C}_{7} \mathrm{H}_{16} \mathrm{O}_{3}$ & 1,06 & 0,72 \\
\hline 10 & 7,58 & 1,1-dietoxi-propano & $\mathrm{C}_{7} \mathrm{H}_{14} \mathrm{O}_{2}$ & - & 1,33 \\
\hline 11 & 8,38 & Furfural & $\mathrm{C}_{5} \mathrm{H}_{4} \mathrm{O}_{2}$ & 5,48 & 8,79 \\
\hline 12 & 9,34 & 2-furanometanol & $\mathrm{C}_{5} \mathrm{H}_{6} \mathrm{O}_{2}$ & 3,85 & - \\
\hline 13 & 11,01 & 2-metil, 2-ciclopenten-1-ona & $\mathrm{C}_{6} \mathrm{H}_{8} \mathrm{O}$ & 1,70 & 2,15 \\
\hline 14 & 11,34 & Butirolactona & $\mathrm{C}_{4} \mathrm{H}_{6} \mathrm{O}_{2}$ & 1,29 & 1,52 \\
\hline 15 & 11,40 & $2(5 \mathrm{H})$-furanona & $\mathrm{C}_{4} \mathrm{H}_{4} \mathrm{O}_{2}$ & 1,57 & 1,11 \\
\hline 16 & 11,84 & 2-hidroxi-2-ciclopenten-1-ona & $\mathrm{C}_{6} \mathrm{H}_{8} \mathrm{O}$ & 3,99 & 3,02 \\
\hline 17 & 11,94 & Dietoxiacetato de etilo & $\mathrm{C}_{8} \mathrm{H}_{16} \mathrm{O}_{4}$ & - & 1,33 \\
\hline 18 & 13,08 & 5-metil-2-furanocarboxaldeído & $\mathrm{C}_{6} \mathrm{H}_{6} \mathrm{O}_{2}$ & 1,08 & 1,84 \\
\hline 19 & 13,87 & Fenol & $\mathrm{C}_{6} \mathrm{H}_{6} \mathrm{O}$ & - & 0,97 \\
\hline 20 & 14,92 & 2,5 - dietoxitetrahidro furano & $\mathrm{C}_{8} \mathrm{H}_{16} \mathrm{O}_{3}$ & 5,67 & 4,37 \\
\hline 21 & 15,32 & 2-hidroxi-3-metil,2-ciclopenten-1-ona & $\mathrm{C}_{6} \mathrm{H}_{8} \mathrm{O}_{2}$ & 3,33 & 2,64 \\
\hline 22 & 17,14 & 1,1- dietoxi- pentano & $\mathrm{C}_{9} \mathrm{H}_{20} \mathrm{O}_{2}$ & 1,36 & - \\
\hline 23 & 17,29 & 2- metoxi - fenol & $\mathrm{C}_{7} \mathrm{H}_{8} \mathrm{O}_{2}$ & 1,58 & 1,61 \\
\hline 24 & 17,54 & Dihidro-4-hidroxi- 2(3H) - furanona & $\mathrm{C}_{4} \mathrm{H}_{6} \mathrm{O}_{3}$ & 2,67 & - \\
\hline 25 & 19,38 & 5,5-dietoxi-2-pentanona & $\mathrm{C}_{9} \mathrm{H}_{18} \mathrm{O}_{3}$ & 0,65 & - \\
\hline 26 & 20,40 & Creosol & $\mathrm{C}_{8} \mathrm{H}_{10} \mathrm{O}_{2}$ & 0,61 & - \\
\hline 27 & 20,71 & Catecol & $\mathrm{C}_{6} \mathrm{H}_{6} \mathrm{O}_{2}$ & 2,14 & - \\
\hline 28 & 22,40 & 3-metoxi - 1,2-benzenediol & $\mathrm{C}_{7} \mathrm{H}_{8} \mathrm{O}_{3}$ & 1,66 & - \\
\hline 29 & 22,59 & 2-metil, 2- ácido propanóico metil propil ester & $\mathrm{C}_{8} \mathrm{H}_{16} \mathrm{O}_{2}$ & 1,00 & - \\
\hline 30 & 23,79 & 2-metoxi - 4 - vinilfenol & $\mathrm{C}_{9} \mathrm{H}_{10} \mathrm{O}_{2}$ & 0,76 & - \\
\hline 31 & 24,83 & 2,6-dimetoxi - fenol & $\mathrm{C}_{8} \mathrm{H}_{10} \mathrm{O}_{3}$ & 4,10 & 2,46 \\
\hline 32 & 24,95 & 1,1-dietoxi nonano & $\mathrm{C}_{13} \mathrm{H}_{28} \mathrm{O}_{2}$ & 0,57 & - \\
\hline 33 & 25,03 & 3,4-dimetoxi-fenol & $\mathrm{C}_{8} \mathrm{H}_{10} \mathrm{O}_{3}$ & 0,37 & - \\
\hline 34 & 27,22 & 3-hidroxi-4-metoxi ácido benzoico & $\mathrm{C}_{8} \mathrm{H}_{8} \mathrm{O}_{4}$ & 1,53 & 1,08 \\
\hline 35 & 27,28 & 2-metoxi-4-(1-propenil)-fenol & $\mathrm{C}_{10} \mathrm{H}_{12} \mathrm{O}_{2}$ & 0,82 & - \\
\hline 36 & 28,93 & Levoglucosana & $\mathrm{C}_{6} \mathrm{H}_{10} \mathrm{O}_{5}$ & 2,20 & - \\
\hline 37 & 29,13 & 5-tert - butilpirogallol & $\mathrm{C}_{10} \mathrm{H}_{14} \mathrm{O}_{3}$ & 0,94 & - \\
\hline 38 & 30,04 & 2,5-dimetoxI-4-metIlbenzaldehido & $\mathrm{C}_{10} \mathrm{H}_{12} \mathrm{O}_{3}$ & 1,51 & - \\
\hline 39 & 30,90 & 2,6-dimetoxi-4-(2-propenil) - fenol & $\mathrm{C}_{11} \mathrm{H}_{14} \mathrm{O}_{3}$ & 0,36 & - \\
\hline 40 & 31,98 & 4-(4-hidroxi-3-metoxifenil)-2-butanona & $\mathrm{C}_{11} \mathrm{H}_{14} \mathrm{O}_{3}$ & 0,39 & - \\
\hline 41 & 32,18 & 4-hidroxi-3,5-dimetoxi -benzaldehido & $\mathrm{C}_{9} \mathrm{H}_{10} \mathrm{O}_{4}$ & 0,47 & - \\
\hline 42 & 33,06 & 2-hidroxi-4-isopropil-7-metoxitropone & $\mathrm{C}_{11} \mathrm{H}_{14} \mathrm{O}_{3}$ & 1,08 & - \\
\hline 43 & 33,76 & 1-(4-hidroxi-3,5-dimetoxifenil)- etanona & $\mathrm{C}_{10} \mathrm{H}_{12} \mathrm{O}_{4}$ & 0,57 & - \\
\hline
\end{tabular}




\begin{tabular}{l|l|l|l|l|l}
\hline 44 & 34,57 & Ácido 3,5-dimetoxi-4-Hidroxifenilacético & $\mathrm{C}_{10} \mathrm{H}_{12} \mathrm{O}_{5}$ & 0,95 & - \\
\hline
\end{tabular}

Nos testes de pirólise foram identificados componentes pertencentes a classes como ácidos, cetonas, aldeídos, fenóis, ésteres, éteres, açúcares e álcoois. Para os compostos com funções orgânicas mistas, como duas ou mais, foram consideradas as nomenclaturas oficiais como predominantes. Por exemplo, 1-hidróxi-2butanona, classificada como cetona, 2-furanometanol como furano, 2,2-dietoxi- etanol classificado como álcool e 2-hidroxietil-acetato como éster. Segundo a IUPAC (International Union of Pure Applied Chemistry), a ordem de preferência na escolha da função principal é ácido, amida, aldeído, cetona, álcool, amina, éter e haleto [12]. Os compostos da fase líquida para a biomassa de eucalipto foram agrupados por classes e o rendimento apresentado na Figura 5.

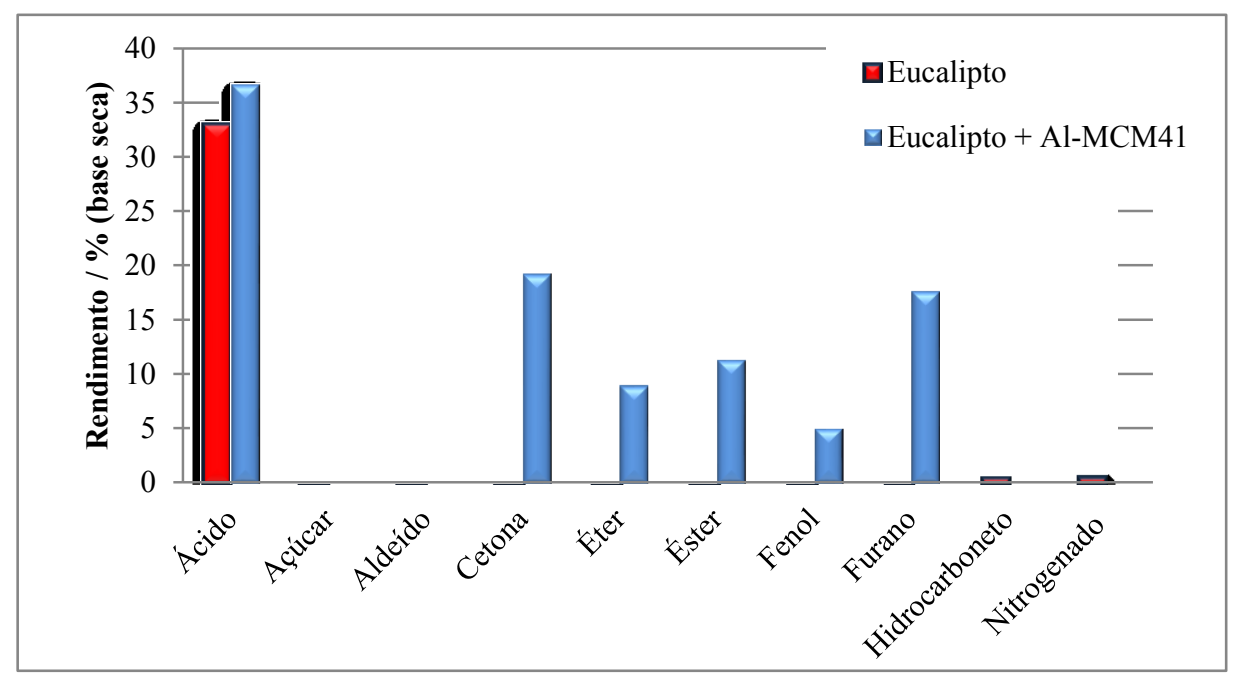

Figura 5: Distribuição das áreas percentuais das classes de compostos identificados no bio-óleo.

\section{DISCUSSÃO}

Na Figura 1 foi apresentada a micrografia da amostra Al-MCM-41 constituída de partículas com geometria próxima à de um prisma hexagonal $[18,19]$.

Sabe-se que as peneiras moleculares são constituídas por sílica e a superfície da sílica $\left(\mathrm{SiO}_{2}\right)$ forma com facilidade grupos silanóis ( $\mathrm{Si}-\mathrm{OH}$ ), os quais são considerados sítios ácidos de Bronsted. Porém, esses grupos apresentam acidez fraca ou moderada.

Para aumentar a estabilidade desse material, é necessário aumentar a acidez dos sítios ácidos de Bronsted que pode ser acrescida pela substituição isomórfica dos átomos de silício tetravalente por cátions trivalentes como, por exemplo, o alumínio, que consequentemente, gerará uma carga negativa a rede. Além da acidez de Bronsted, os aluminiossilicatos também possuem acidez de Lewis, associada ao alumínio substituído isomorficamente pelo silício. A acidez destes materiais depende essencialmente da localização e do conteúdo de alumínio na estrutura do silicato, além do estado de coordenação do alumínio.

Os resultados de composição elementar, composição imediata, poder calorifico, além das propriedades inorgânicas foram todos compatíveis com os obtidos por autores como $[1,5,10]$.

CORTEZ et al. [1] estudaram as biomassas de pinus, eucalipto, casca de arroz, bagaço de cana e casca de coco e observaram resultados análogos para todas as amostras.

RAMBO et al. [4] ao estudarem as propriedades das biomassas para o uso energético observaram valores médios de oxigênio de $59 \%$ para casca de arroz, casca e talos de banana e grama. Os valores de poder

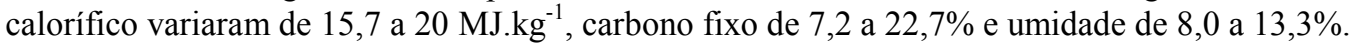

Por análise termogravimétrica da biomassa de eucalipto foi possível observar que o processo de perda de massa se desenvolve basicamente em três etapas principais. A primeira até $220{ }^{\circ} \mathrm{C}$, correspondente a $7 \%$ de perda, onde a biomassa absorve calor liberando a umidade na forma de vapor de água e entre 110 e $180{ }^{\circ} \mathrm{C}$, ocorrem reações de desidratação que envolvem os grupos - $\mathrm{OH}$ presentes nas moléculas dos polissacarídeos. 
Nesta fase, o dióxido de carbono, monóxido de carbono e água são retirados a partir da matriz de biopolímero.

A segunda etapa de perda de massa ocorre entre 230 e $390{ }^{\circ} \mathrm{C}$, representando $64 \%$ de perda de massa, quando começam as reações típicas da pirólise. Na faixa entre 230 e $290{ }^{\circ} \mathrm{C}$, acontece a degradação da hemicelulose, sendo parcialmente degradada a celulose e a lignina. É importante salientar que nesse intervalo de temperatura ocorre a formação dos compostos intermediários como açúcares, além de monóxido de carbono, dióxido de carbono e ácido acético na forma de voláteis de acordo com Luengo e colaboradores (2009). Em torno de $370{ }^{\circ} \mathrm{C}$ é alcançada a máxima taxa de degradação da hemicelulose e entre 290 e $400{ }^{\circ} \mathrm{C}$ ocorre a degradação total da de celulose [20]. Nessa fase, ocorre a quebra de ligações glicosídicas dos polissarídeos, dando lugar a uma grande emissão de voláteis, compostos por vapores orgânicos e altas concentrações de CO, $\mathrm{H}_{2}, \mathrm{CH}_{4}$ e $\mathrm{CO}_{2}$, verificando-se grande formação de ácido acético, metanol e acetona. O alcatrão começa se tornar predominante com o aumento da temperatura. A terceira etapa desenvolve-se acima de $390{ }^{\circ} \mathrm{C}$, representando $24 \%$ de perda de massa, quando se completa a degradação da lignina, ocorrendo a formação de alcatrões pesados e de hidrocarbonetos aromáticos [21].

Por microscopia eletrônica de varredura foi possível observar a estrutura fibrosa com feixes unidos pela lamela media semelhante ao observado em outras fibras lignocelulósicas. As fibras dispostas em feixes indicam a disposição original nos cavacos de madeira que apresentam ocorrência mesmo após serem trituradas. São apresentadas seções longitudinais da fibra com um grande número de fibrilas, além de material conciso e de ligação. As fibrilas são constituidas por um grande número de células, justapostas e internamente ligadas por substancias de origem péctica. As fibras são ocas, constituidas por macromoléculas de celulose, recobertas e unidas, umas as outras por uma matriz de lignina e hemicelulose [22].

A reação de pirólise rápida de eucalipto foi realizada com objetivo de avaliar a influencia do catalisador Al-MCM41 no rendimento das fases e na distribuição dos produtos do bio-óleo. O cálculo de rendimento dos produtos (bio-óleo, bio-carvão e bio-gás) foi realizado considerando base seca (\%), ou seja, desprezando a umidade existente na biomassa. Pode-se observar que os rendimentos médios de bio-óleo foram de $44,6 \%$, de 16,9 \% de bio-gás e 38,5 \% de bio-carvão. Pesquisadores como Kumar, Panda e Singh (2010) estudaram a otimização do processo de pirólise para produção de bio-óleo a partir da madeira de eucalipto e observaram um rendimento de líquido entre 44,1 e $50 \%$ para temperaturas entre 350 e $500{ }^{\circ} \mathrm{C}$. Assim como neste trabalho os autores identificaram um teor de bio-carvão em torno de $35 \%$ e de bio-gás na mesma ordem de grandeza [23]

Ao realizar a pirólise catalítica, observou-se uma redução da fase líquida de $46,6 \% \mathrm{~m} / \mathrm{m}$ para $38,7 \%$ e um aumento de bio-gás de $16,9 \%$ para $27,3 \%$, semelhante aos obtidos por [14,15]. Segundo [24], a redução do rendimento líquido pirolítico que ocorreu na pirólise catalítica comparada com o rendimento do teste térmico, está associada ao craqueamento de vapores de pirólise na superfície dos catalisadores, resultando na formação de produtos gasosos.

A presença do catalisador não afetou de forma significativa a produção de bio-carvão. A grande variação entre os testes térmicos e catalíticos se evidenciam após a pirólise da biomassa, quando os vapores formados passaram pelo leito catalítico, modificando, assim, as características do bio-óleo e do bio-gás.

Ao analisar a distribuição dos produtos da pirólise pode-se observar uma porcentagem em área de $25,51 \%$ para o ácido acético, valor bastante significativo ao comparar com os obtidos por autores como [25] que obtiveram 7,33\% para biomassa de pinhos, e [26,27] que identificaram porcentagens de $19,2 \% \mathrm{~m} / \mathrm{m}$ e $21,86 \% \mathrm{~m} / \mathrm{m}$ para pirólise de cana de açúcar, respectivamente. A maior produção de ácido acético ocorre pela desacetilação da hemicelulose e, em menor proporção, pela cisão dos anéis da celulose e posterior rearranjo. Além disso, o ácido acético pode decorrer do craqueamento das cadeias laterais da lignina.

A produção de ácido acético na pirólise catalítica do eucalipto foi em porcentagem em área de 35,6 \%. Autores como [12] indicaram em seu trabalho a não uniformidade na atividade dos catalisadores e nas propriedades do líquido pirolítico e sugeriram uma observação mais detalhada da seletividade de certos grupos funcionais ou classes químicas.

Estudos mostraram que a pirólise na presença de zeólita ZSM-5 foram mais ativa para compostos aromáticos, furanos e fenóis, enquanto que a Al-MCM-41 aumentava a porcentagem de fenóis pesados e redução da quantidade de ácidos orgânicos. Por exemplo, ao realizar pirólise da casca de arroz foi identificado uma porcentagem em área, de 39,61\% de líquido, $18,47 \%$ de gás e $41,92 \%$ de carvão. Ao adicionar o catalisador Al-MCM-41 o balanço de massa passou a 39,98\% m/m de líquido, $18,80 \%$ de gás e $43,15 \%$ de carvão. Ou seja, uma alteração pouco significativa [12].

Outro produto identificado com porcentagem em área significativa, $10 \%$, foi o etil acetato ou acetato de etila $(\mathrm{RT}=2,95)$ na pirólise na presença do catalisador. Esse composto apresenta diferentes aplicações na 
indústria química, sendo utilizado principalmente como solvente de tintas, diluentes, revestimentos, adesivos, esmaltes e produtos farmacêuticos.

Assim como o ácido acético, o 1- hidróxi -2-propanona e os furanos estão associados a degradação da hemicelulose, enquanto a decomposição da celulose, induz principalmente a aldeídos e sacarídeos, dióxido de carbono e água [23]. O 1- hidróxi -2-propanona foi o composto com segunda maior porcentagem em área, com valor médio de 7,9\% em tempo de retenção de 3,87 minutos.

A produção de 1,1-dietóxi etano pode ser provavelmente derivada da pirólise de óleos essenciais de eucalipto obtido entre 200 e $300{ }^{\circ} \mathrm{C}$ [28].

Um fator importante é o aumento na produção de furfural na pirólise do eucalipto sendo acentuada na presença do catalisador. Esse composto é formado a partir de reações de abertura do anel da unidade de celulose e rearranjo das unidades do polímero de celulose e de hemicelulose, assim como pode ser proveniente de reações secundárias da levoglucosana conforme é mostrado por DONG e colaboradores [29].

\section{CONCLUSÕES}

A análise de microscopia eletrônica de varredura indicou a morfologia hexagonal do catalisador Al-MCM-41 e, por fluorescência de raios X, foram confirmadas as composições químicas dos catalisadores e, consequentemente, a razão silício alumínio.

A partir da análise elementar, imediata e poder calorífico foi possível obter informações sobre propriedades inerentes a biomassa.

A análise termogravimétrica possibilitou identificar as regiões de perda de massa associadas à composição dos materiais lignocelulósicos. A partir da perda de massa da biomassa em função da temperatura, observaram-se as regiões de degradação dos constituintes associados à celulose, hemicelulose e lignina.

O rendimento de produtos obtido na pirólise rápida do eucalipto foi compatível a literarura, com predominância da fase líquida, seguida de bio-carvão e bio-gás. A presença de catalisador favoreceu a ocorrência de bio-gás proveniente do craqueamento da bio-óleo no leito.

Os principais grupos de compostos formados foram ácidos, cetonas, furanos, fenois, éster, eter, aldeído, açúcar, álcool, hidrocarbonetos e nitrogenados.

O principal composto identificado na pirólise da biomassa foi o ácido acético, este fato foi associado a desacetilação da hemicelulose, mecanismo da cisão dos anéis da celulose e craqueamento das cadeias laterais da lignina.

\section{BIBLIOGRAFIA}

[1] CORTEZ, L. A. B., LORA, E. E. S., AYARZA, J. A. C. "Biomassa no Brasil e no mundo", Biomassa para energia, cap. 1, 2009.

[2] BEN - Balanço Energético Nacional 2015 - Ano base 2014: Relatório Síntese. Brasil. Empresa de Pesquisa Energética. Rio de Janeiro, EPE, pp. 62, 2015.

[3] TERRAPON-PFAFF, J. C., FISCHEDICK, M., MONHEIM, H., "Energy potentials and sustainabilitythe case of sisal residues in Tanzania", Energy for Sustainable Development, v. 16, pp. 312-319, 2012.

[4] RAMBO, M. K. D., SCHMIDT, F. L., FERREIRA, M. M. C., "Analysis of the lignocellulosic components of biomass residues for biorefinery opportunities", Talanta, v. 144, pp. 696-703, 2015.

[5] COUTO. L., MULLER, M. D. Florestas Energéticas no Brasil, In: Biomassa para energia, cap. 4, pp. 93 , 2009.

[6] SMETS, K., SCHREURS, S., CARLEER, R., et al., "Valorization of raspberry seed cake by flash and slow pyrolysis: Product yield and characterization of the liquid and solid fraction", Journal of Analytical and Applied Pyrolysis, v. 107, pp. 289-297, 2014.

[7] BRIDGWATER, T. "Biomass for energy", Journal of the Science of Food and Agriculture, v. 86, n. 12, pp. 1755-1768, 2006.

[8] WHYTE, H. E., LOUBAR, K., AWAD, S., et al., "Pyrolytic oil production by catalytic pyrolysis of refuse-derived fuels: Investigation of low cost catalysts", Fuel Processing Technology, v. 140, pp. 32-38, 2015.

[9] ALCALA, A., BRIDGWATER A. V. "Upgrading fast pyrolysis liquids: Blends of biodiesel and pyrolysis oil”, Fuel, v. 109, pp. 417-426, 2013. 
[10] ALMEIDA, M. B. B. Bio-óleo a partir da pirólise rápida, térmica ou catalítica, da palha da cana-deaçúcar e seu co-processamento com gasóleo em craqueamento catalítico, Tese de D.Sc, Escola de Química, UFRJ, Rio de Janeiro, RJ. 2008.

[11] HUANG, Y., WEI, L., JULSON, J., et al., "Converting pine sawdust to advanced biofuel over HZSM-5 using a two-stage catalytic pyrolysis reactor", Journal of Analytical and Applied Pyrolysis, v. 111, pp. 148$155,2015$.

[12] BAKAR, M. S. A., TITILOYE, J. O. "Catalytic pyrolysis of rice husk for bio-oil production", Journal of Analytical and Applied Pyrolysis, v. 103, pp. 362-368, 2013.

[13] ANTONAKOU, E., LAPPAS, A., NILSEN, H. M., et al., "Evaluation of various types of Al-MCM-41 materials as catalysts in biomass pyrolysis for the production of bio-fuels and chemicals", Fuel, v. 85, pp. $2202-2212,2006$.

[14] AHO. A., KUMAR, N., ERÄNEN, K., et al., "Catalytic pyrolysis of woody biomass in a fluidized bed reactor: Influence of the zeolite structure”, Fuel, v. 87, pp. 2493-2501, 2008.

[15] ADAM, J., BLAZSÓ, M., MÉSZÁROS, E. "Pyrolysis of biomass in the presence of Al-MCM-41 type catalysts", Fuel, v. 84, n. 12-13, pp. 1494-1502, 2005.

[16] BARBOSA, F. S., SANTOS, A. C. B., SILVA. M.I. P. "Resistance to poisoning by nitrogen compounds of NiMo/Al-MCM-41 hydrocracking”, Catalysts Today, v.98, pp. 109-113, 2004.

[18] PAULINO, A. A. D. Degradação térmica da bora oleosa de petróleo com materiais nanoestruturados Al-MCM-41 e Al-SBA-15. Tese de D.Sc., UFRN, Natal, RN, 2011.

[19] CARMO JR, A.C., SOUZA, L.K.C., COSTA, C.E.F. "Production of biodiesel by esterefication of palmitic acid over mesoporous aluminosilica e Al-MCM-41”, Fuel, v. 88, pp. 461-468, 2009.

[20] HILLIG, E. Viabilidade de técnica de produção de compósitos de polietileno (HDPE) reforçados com resíduos de madeira e derivados das indústrias moveleiras. Tese de D.Sc., UFPR, Curitiba, PR, 2006.

[21] LUENGO, C. A., FELFLI, F. E. F., BEZZON,G. Pirólise e torrefação de biomassa. cap. 10, 2009.

[22] SANTOS, R. P. de O. Compósitos baseados em PET reciclado, fibras de sisal e plasticizantes oriundos de fontes renováveis: estudo do processamento e propriedades dos materiais, Dissertação de M. Sc. USP, São Paulo, 2012.

[23] AMUTIO M., LOPEZ G., ALVAREZ J., et al., "Flash pyrolysis of forestry residues from the Portuguese Central Inland Region within the framework of the BioREFINA-Ter project", Bioresource Technology, v. 129, pp. 512-518, 2013.

[24] NAQVI, S. R., UEMURA, Y., YUSUP, S. B. "Catalytic pyrolysis of paddy husk in a drop type pyrolyzer for bio-oil production: The role of temperature and catalyst", Journal of Analytical and Applied Pyrolysis, v. 106, pp. 57-62, 2014.

[25] GREENHALF, C. E., NOWAKOWSKI, D. J., YATES, N., et al., "The influence of harvest and storage on the properties of and fast pyrolysis products from Miscanthus x giganteus", Biomass and Bioenergy, v. 56, pp. 247-259, 2013

[26] MACHADO, M. A. Produção e Tratamento Catalítico de Bio-Óleo Produzido a partir da Pirólise do Bagaço de Cana-de-Açúcar. Dissertação de M. Sc., UFRJ, Rio de Janeiro, RJ, 2013.

[27] SILVA, S. S. Catalisadores à base de estanha sulfatada para tratamento dos vapores de pirólise do bagaço de cana-de-açúcar, Dissertação de M. Sc., UFRJ, Rio de Janeiro, pp. 98, 2014.

[28] MARTINS, A. F., DINIZ, J., STAHL, J. A., et al., "Caracterização dos produtos líquidos e do carvão da pirólise de serragem de eucalipto”, Química Nova, v. 30, n. 4, pp. 873-878, 2007.

[29] DONG, C.-Q., ZHANG, Z-F., LU, Q., et al., "Characteristics and mechanism study of analytical fast pyrolysis of poplar wood", Energy Conversion and Management, v. 57, pp. 49-59, 2012. 